\section{Commentary: Building an academic cardiothoracic surgical program: The Baylor experience}

\author{
Alexander Schutz, MD, ${ }^{\mathrm{a}, \mathrm{b}}$ Scott A. LeMaire, MD, ${ }^{\mathrm{a}, \mathrm{c}}$ \\ Barbara W. Trautner, MD, PhD, ${ }^{\mathrm{a}, \mathrm{d}, \mathrm{e}}$ and \\ Todd K. Rosengart, MD ${ }^{\mathrm{a}, \mathrm{c}}$
}

The premise of the academic surgeon pursuing research and teaching while rendering clinical care has been challenged since its conception by Halsted as one of the "four horsemen" of Johns Hopkins more than a century ago. Although a minority in the medical community, surgeons' contributions to medical innovation have nevertheless been robust and longstanding. From Lister's discovery of the principles of antisepsis to Starzl's advancement of solid organ transplantation, surgeons' academic accomplishments have claimed Nobel Prize stature in the leadership of academic medicine.

And yet, notwithstanding the high research impact of surgeon-scientists, the academic success of all clinician-

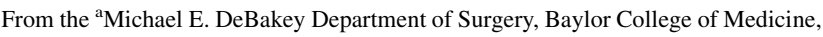
Houston, Tex; ${ }^{b}$ Division of Cardiothoracic Surgery, Michael E. DeBakey Veterans Affairs Medical Center, Houston, Tex; ${ }^{\mathrm{c}}$ Department of Cardiovascular Surgery, Texas Heart Institute, Houston, Tex; ${ }^{\mathrm{d}}$ Section of Health Services Research, Department of Medicine, Baylor College of Medicine, Houston, Tex; and ${ }^{\mathrm{e}}$ Center for Innovations in Quality, Effectiveness, and Safety, Michael E. DeBakey Veterans Affairs Medical Center, Houston, Tex

Dr LeMaire's work is supported in part by the Jimmy and Roberta Howell Professorship in Cardiovascular Surgery at Baylor College of Medicine. Dr Trautner's work is supported in part by the Houston Veterans Affairs Health Services Research \& Development Center for Innovations in Quality, Effectiveness, and Safety (CIN 13-413).

Disclosures: Dr LeMaire has served as a consultant for Terumo Aortic, Cerus, and Baxter Healthcare; as an Advisory Board Member for Biom'up and Acer Therapeutics; and as a investigator for clinical studies sponsored by Terumo Aortic, CytoSorbents, Baxter Healthcare, Medtronic, and W.L. Gore \& Associates. Dr Trautner has received funding from Genentech. All other authors reported no conflicts of interest.

The Journal policy requires editors and reviewers to disclose conflicts of interest and to decline handling or reviewing manuscripts for which they may have a conflict of interest. The editors and reviewers of this article have no conflicts of interest.

The views expressed in this article are those of the authors and do not necessarily reflect the position or policy of the Department of Veterans Affairs or the United States government.

Received for publication April 24, 2021; revisions received April 24, 2021; accepted for publication April 26, 2021; available ahead of print May 3, 2021.

Address for reprints: Todd K. Rosengart, MD, Michael E. DeBakey Department of Surgery, Baylor College of Medicine, 1709 Dryden Rd, Suite 1500, Houston, TX 77030 (E-mail: todd.rosengart@bcm.edu).

J Thorac Cardiovasc Surg 2022;163:1435-6

0022-5223/\$36.00

Copyright (c) 2021 by The American Association for Thoracic Surgery

https://doi.org/10.1016/j.jtcvs.2021.04.081
}

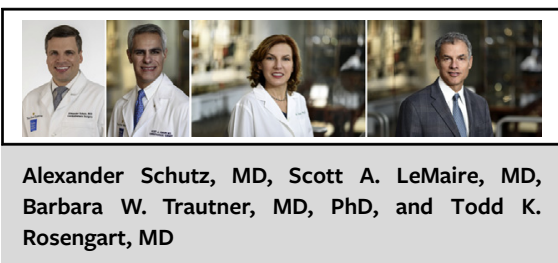

CENTRAL MESSAGE

Multiple strategies are available to programs large and small to support, promote, and enhance academic surgical programs.

investigators faces growing challenges from new clinical and regulatory burdens. ${ }^{1-3}$ Yarboro and colleagues in their accompanying commentary note several important strategies to combat these challenges. ${ }^{4}$ Like our University of Virginia colleagues, we have found that the mainstay of academic accomplishment is a culture of excellence, as embodied in the legacy of our department's namesake, Dr Michael E. DeBakey. At the core of this culture of excellence is a robust academic infrastructure, supplemented by the power of a "just culture" wherein innovation is propelled by a diversity of thought and the freedom to speak out to respectfully question accepted norms of practice.

Invaluable in our culture are our academic relative value unit and faculty promotion programs, which leverage the transparency of point systems recalibrated annually by our department mission committees to incentivize academic priorities - the former an expanded version of a model reported by the University of Virginia group. ${ }^{6,7}$ Our 70-member Office of Surgical Research likewise reinforces our commitment to research with "close to home" clinical trials, grant management, and biostatistical and other support for our faculty and trainees. Together with our internal grant review program, through which each proposal for external funding is reviewed by peers with extramural funding, this academic support infrastructure has catalyzed a 6-fold growth in our research portfolio over the past 5 years to more than 200 translational research grants and clinical trials.

The academic aspirations of our faculty and trainees are encouraged through other resources as well. Our Office of Education supported one of our junior residents in realizing her vision of a 7-year Global Surgery Residency, the only such National Resident Matching Program-listed track in the United States. ${ }^{8}$ Our multifaceted research engagement program (interactive educational workshops plus support 
from our research infrastructure) was associated with an increase in publications by our general surgery residents. ${ }^{9}$ Our seed grant program, highlighted annually during our alldepartment Research Day, has returned more than \$5.7 million in extramural funding on $\$ 340,000$ invested. Our Surgery Incubator sponsors faculty prototyping grants and Speed Networking with collaborators at neighboring institutions, advancing more than 50 inventions into patent disclosures and even commercial entities. Annually, our Continuing Medical Education office sponsors conferences drawing more than 1000 participants, and our Communications office garners more than a million social media impressions.

A NASA-inspired human performance analytic embedded in our clinical quality conferences exemplifies our just culture, supporting nonjudgmental identification and amelioration of "human factors" in surgical complications. $^{9,10}$ A collaboration with the American Airlines Flight Safety Academy yielded online error reporting and leadership training programs for residents and faculty. Finally, our Social Equity Committee guides us in exploring potential gender and racial biases in our department. They led us this summer in a compelling grand rounds on bias, featuring a police violence victim interviewed by his cousin, a faculty member.

Our top-decile reputational score in US News and World Report and our Association of American Medical Colleges faculty satisfaction score of $85 \%-15$ points higher than our cohort peers-reflect the return on investment that fostering academic support can have on department vitality. Although creating extensive infrastructure may be challenging for smaller divisions or departments, we believe the model of cultural support for the academic mission can be advantageous for any program.

\section{References}

1. Keswani SG, Moles CM, Morowitz M, Zeh H, Kuo JS, Levine MH, et al. The future of basic science in academic surgery: identifying barriers to success for surgeon-scientists. Ann Surg. 2017;265:1053-9.

2. Narahari AK, Mehaffey JH, Chandrabhatla AS, Baderdinni PK, Weiderhold A, Cook IO, et al. A 30-year analysis of National Institutes of Health-funded cardiac transplantation research: surgeons lead the way. J Thorac Cardiovasc Surg. July 5, 2020 [Epub ahead of print].

3. Narahari AK, Mehaffey JH, Hawkins RB, Charles EJ, Baderdinni PK, Chandrabhatla AS, et al. Surgeon scientists are disproportionately affected by declining NIH funding rates. J Am Coll Surg. 2018;226:474-81.

4. Yarboro LT, Mehaffey JH, Charles EJ, Kron IL. How to build and sustain an academic cardiothoracic surgical program. J Thorac Cardiovasc Surg. 2022;163: 1431-4.

5. Khatri N, Brown GD, Hicks LL. From a blame culture to a just culture in health care. Health Care Manage Rev. 2009;34:312-22.

6. LeMaire SA, Trautner BW, Ramamurthy U, Green SY, Zhang Q, Fisher WE, et al. An academic relative value unit system for incentivizing the academic productivity of surgery faculty members. Ann Surg. 2018;268:526-33.

7. Schroen AT, Thielen MJ, Turrentine FE, Kron IL, Slingluff CL Jr. Research incentive program for clinical surgical faculty associated with increases in research productivity. J Thorac Cardiovasc Surg. 2012;144:1003-9.

8. Davis RW, Sherif YA, Vu MT, Shilstone H, Scott B, Olutoye OO, et al. Personalized graduate medical education and the global surgeon: training for resourcelimited settings. Acad Med. 2021;96:384-9.

9. Frankel WC, Scott BG, Massarweh NN, Silberfein EJ, Zhang Q, Rosengart TK, et al. A multifaceted research engagement program improved the academic productivity of general surgery residents. J Surg Educ. 2020;77:1082-7.

10. Suliburk JW, Buck QM, Pirko CJ, Massarweh NN, Barshes NR, Singh H, et al. Analysis of human performance deficiencies associated with surgical adverse events. JAMA Netw Open. 2019;2:e198067. 